\title{
$\mathrm{VCM}$ 액추에이터의 전자기력을 이용한 $\mathrm{HDD}$ 래치 설계
}

\section{A HDD Latch Design Using Electro-magnetic Force of VCM Actuators}

\author{
김 경 호*. 오 동 호 ${ }^{1}$. 신 부 현**. 이 승 엽 ${ }^{2}$ \\ Kyung-Ho Kim, Dong-Ho Oh, Bu-Hyun Shin and Seung-Yop Lee \\ (2009년 3월 11일 접수 ; 2009년 7월 22일 심사완료)
}

\begin{abstract}
Key Words : Magnetic Latch(자석 래치), VCM Actuator(보이스 코일 모터 액추에이터), Electromagnetic Force (전자기력), Inertia Latch(관성 래치), Load/Unload(로드/언로드), Ramp(램프), Contact Start Stop (접촉 구동 방식), Hard Disk Drive(하드디스크드라이브)
\end{abstract}

\begin{abstract}
Various types of latch designs for hard disk drives using load/unload mechanism have been introduced to protect undesired release motions of a voice coil motor(VCM) actuator from sudden disturbances. Recently, various inertia-type latches have been widely used because locking performance is better than that of other types of latch. However there has been a limit in the inertia type in order to guarantee perfect latch and unlatch operations because of changes in latch/unlatch conditions due to mechanical tolerance and temperature-dependent friction. In this paper, a reliable and robust magnetic latch mechanism is proposed through only simple modifications of coil and yoke shapes in order to overcome the mechanical limit of current inertia-type latches. This new magnetic latch does not have only a simple structure but it also ensures reliable operations and anti-shock performance. The operating mechanism of the proposed latch is theoretically analyzed and optimally designed using an electromagnetic simulation.
\end{abstract}

\section{1. 서 론}

최근 컴퓨터와 네트워크를 통한 정보의 양이 많 아지면서 주저장장치로서 사용되는 하드디스크 드 라이브(HDD)는 고기록밀도를 달성하기 위한 치열 한 기술 개발이 이루어지고 있다. 현재 대부분의 $\mathrm{HDD}$ 에서는 정지시 마그네틱 헤드가 디스크의 일 정 지역에 접촉되어있는 접촉 구동(CSS; contact start stop) 방식이 사용되어왔다. 그러나 노트북, 넷

$\dagger^{1}$ 교신저자; 정회원, 충남대학교 기계공학과

E-mail : dongho@cnu.ac.kr

Tel : (042)821-6576, Fax : (042)822-5642

$\uparrow^{2}$ 교신저자; 정회원, 서강대학교 기계공학과

E-mail : sylee@sogang.ac.kr

Tel : (02)705-8638, Fax : (02)712-0977

* 삼성전자 반도체총괄

** 서강대학교 기계공학과
북과 같이 주로 모바일 장치에 사용되는 2.5 인치 이하 크기의 $\mathrm{HDD}$ 는 비동작시 헤드를 디스크로부 터 분리하는 로드/언로드(load/unload) 방식이 사용 되고 있다. 또한, 3.5 인치 $\mathrm{HDD}$ 에서도 $500 \mathrm{~GB} / \mathrm{in}^{2}$ 이 상의 고기록밀도를 달성하기 위해 디스크 기록 영 역을 추가적으로 확보할 수 있는 로드/언로드 방식 을 사용하기 위한 연구가 활발히 이루어지고 있다.

로드/언로드 방식은 비작동시 충격 대응력을 증 가시킬 수 있으며, 디스크와 헤드 사이의 점착과 마 모를 제거할 수 있어 디스크 표면 코팅 두께를 줄 일 수 있다. 또한, 헤드가 비작동시에 언로딩 (unloading) 상태로 있으므로 소비 전력을 줄일 수 있고, 헤드와 디스크 표면과의 간격을 감소시킴으로 선밀도 증가를 통한 저장 용량의 증가를 이룰 수 있다. 또한, 헤드 머지 동작이 필요 없으므로 조립 이 쉽다는 장점을 갖는다 ${ }^{(1)}$.

이러한 장점을 갖는 로드/언로드 방식을 구현하 
기 위해서는 드라이브가 비동작시 외부 충격에 의 해 헤드가 계단형 램프를 벗어나 디스크 표면의 데 이터를 손상시키는 것을 방지해야 한다. 동시에 동 작시에는 헤드가 디스크 위의 데이터 영역으로 이 동하는 것을 방해하지 않고 안전하게 데이터 영역 으로 로딩할 수 있는 래치 시스템이 필수적으로 요 구된다.

현재까지 $\mathrm{HDD}$ 의 래치 시스템과 관련된 연구로 는 유도자기 래치, 공기 유동 래치, 솔레노이드 래 치(solenoid latch), 관성 래치(inertia latch) 등이 있 다. 유도자기 래치의 경우는 요크(yoke)의 슬롯 (slot)을 활용하여 비작동시 액추에이터를 구속하며, 작동시 액추에이터에서 발생하는 힘에 의해 언래치 되는 단순 구조이지만 서보 제어가 어렵고, 초기 전 력이 많이 들어가는 단점이 있다. 공기 유동 래치 (air flow latch)는 비작동시 스프링 힘에 의해 $\mathrm{VCM}$ 액추에이터를 구속하고 작동시 디스크 회전 에 의한 공기 유동에 의해 언래치되는 구조를 가졌 으며, 큰 공간이 필요하다는 단점을 가진다. 솔레노 이드 래치(solenoid latch)는 비작동시 스프링 힘이 액추에이터를 구속하며, 작동시 솔레노이드에 의해 발생하는 전자기력에 의해 잠금 장치를 풀어주는 구조를 가졌으며, 큰 공간이 필요하다.

관성 래치(inertia latch)는 액추에이터와 래치의 관성력의 차이를 이용하여 큰 충격과 넓은 작동 범 위에 대응할 수 있다는 장점을 가지고 있다. 따라서 현재 로드/언로드 방식이 채용된 $\mathrm{HDD}$ 에서는 대부 분 관성 래치가 채용되고 있다. 하지만 드라이브에 액추에이터 작동 조건과 동일한 외부 충격이나 리 바운드(rebound) 충격 조건에 완벽하게 대응하는데 한계를 가진다. 따라서 관성 래치의 한계를 극복하 고 예상치 못한 움직임에서 $\mathrm{VCM}$ 액추에이터의 작 동을 돕기 위하여 여러 가지 다양한 기능을 포함하 는 관성 래치 시스템이 연구되어왔다 ${ }^{(24)}$.

이 연구에서는 기존 관성 래치의 기본 메커니즘 과 관성 래치가 가지는 성능 한계에 대하여 알아본 다. 그리고 $\mathrm{VCM}$ 액추에이터에서 발생하는 전자기 력을 이용한 새로운 개념의 래치 메커니즘을 구현 한다. 이를 통해 코일에 전류가 인가되었을 때, $\mathrm{VCM}$ 엑추에이터에 의해 발생하는 전자기력을 이 용하여 래치가 자동으로 언래치되어 액추에이터가 로딩되도록 한다. 그리고 전류 비인가시 래치 요크
와 $\mathrm{VCM}$ 액추에이터 자석에 의한 인력에 의해 항 상 래치가 락킹(locking)되어 액추에이터를 언로딩 상태로 보호하도록 한다.

\section{2. 기존 관성 래치 시스템}

관성 래치의 기본 작동 메커니즘을 살펴보면, $\mathrm{VCM}$ 액추에이터의 관성(actuator inertia)이 래치의 관성(latch inertia) 보다 커서 외부 충격이 발생하 면, $\mathrm{VCM}$ 액추에이터는 회전 즉, 디스크의 데이터 영역으로 이동하려는 모멘트가 발생한다. 반면, 래 치의 관성은 상대적으로 $\mathrm{VCM}$ 액추에이터보다 작 기 때문에 상호 걸림이 발생해서 래치는 $\mathrm{VCM}$ 액 추에이터가 임의로 회전하여 상기 자기헤드가 램프 를 벗어나 디스크의 기록면으로 이동되는 현상을 방 지한다. 그러나 $\mathrm{VCM}$ 액추에이터 로딩 조건과 유사 하게 원하지 않는 외부 충격과 진동이 발생되거나 $\mathrm{VCM}$ 액추에이터가 래치 후크와 충돌 후 관성력에 의해 재충돌되는 현상인 리바운드 충격(reboundshock)이 발생되었을 때, 관성 래치는 액추에이터를 완전하게 락킹(locking)하는데 한계를 가진다. 따라 서 관성 래치가 가지는 한계를 보완한 여러 메커니 즘이 연구되었다.

삼성종합기술원(SAIT)에 의해 래치 후크(latch hook) 의 끝 단에 후크를 하나 더 추가하는 다중 멈춤쇠 래치(multi-pawl latch) 개념이 연구되어 헤드가 디 스크로 이탈되는 것을 효율적으로 방지하고자 하는 기술이 연구되었다 ${ }^{(2)}$. 또한, Fig. 1 과 같이 작은 충 격에 대하여는 $\mathrm{VCM}$ 액추에이터의 리트랙트 핀 (retract pin)이 자석에 의해 항상 인력이 작용하여 담당하고, 큰 외부 충격에 대해서는 관성 래치에 의 한 관성 영역이 담당하도록 나누어 기존 관성 래치 의 단점을 보완하고자 하는 연구도 진행되었다 ${ }^{(3)}$.

그러나 실제 드라이브 적용시 관성 래치와 핀과 의 홀 공차, 래치 후크의 형상 공차, 자석의 위치 공차 등 관성 래치와 관련된 부품들의 공차에 의한 래치 작동 조건 변화가 발생한다. 또한, 드라이브 작동 온도 변화에 의한 래치 홀의 마찰 변화에 의 한 정지마찰(stiction) 현상이 발생하여 언래치되지 않는 경우도 발생한다.

따라서 위의 제안 방식은 실제 다양한 외부 충격 및 $\mathrm{VCM}$ 액추에이터가 후크와 충돌 후 다시 충돌 


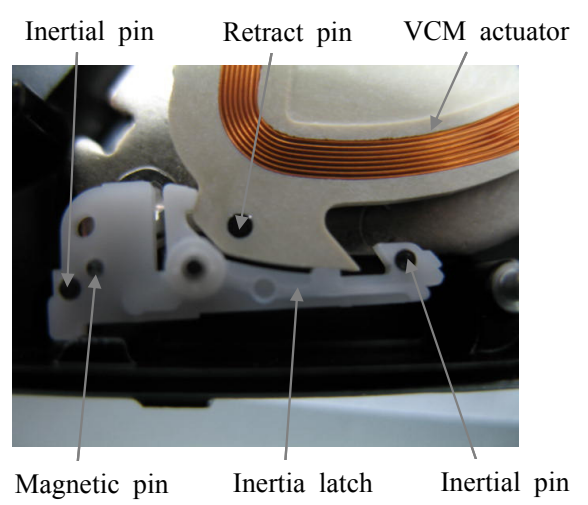

Fig. 1 Typical inertia latch structure

되는 리바운드 현상으로 인한 2 중 충격에 의해 자 기 헤드가 램프를 벗어나는 현상을 방지하는 역할 로는 한계가 있다.

\section{3. 마그네틱 래치 설계}

\section{1 구동 메커니즘}

이 연구에서는 드라이브가 비작동시 다양한 외부 충격과 진동 그리고 액추에이터가 후크와 충돌 후 다시 충돌되는 리바운드로 인한 2 중 충격에 의해 래치가 원하지 않게 언래치되는 문제점을 방지하고 자 $\mathrm{VCM}$ 액추에이터의 코일과 래치의 자석에 의해 발생하는 전자기력을 이용한다. 이 방식은 $\mathrm{VCM}$ 액 추에이터에 전류가 인가되어 로딩될 때 래치가 자 동으로 열리게 되어 언래치된다. 그리고 비작동시에 는 $\mathrm{VCM}$ 액추에이터의 자석과 래치에 부착되어 있 는 요크에 의한 인력에 의해 항상 래치가 $\mathrm{VCM}$ 액 추에이터를 락킹(locking)하게 되어 외부 충격에 대 하여 드라이브를 보호한다. 따라서 기존 래치가 가 지는 한계인 로딩과 락킹을 동시에 하나의 래치 시 스템으로 대응할 수 있어 발생하는 문제점을 근원 적으로 해결할 수 있다. 또한, 이러한 구조를 가지 게 되면 $\mathrm{VCM}$ 오버몰드(overmold)에 리트랙트 핀 과 래치 자석 볼이 필요 없게 되어 기존의 래치 구 조에 비하여 구조가 간단하게 된다.

이 구동 메커니즘을 상세히 설명하면, Fig. 2와 같 이 $\mathrm{VCM}$ 액추에이터와 $\mathrm{VCM}$ 자석이 있으며, $\mathrm{VCM}$ 자석 상하에 요크가 있어 자력을 차폐하도록 설계되 어 있다. 그리고 $\mathrm{VCM}$ 액추에이터 코일에 전류가 인 가되었을 때 래치에 전자기력을 발생하기 위해 래치

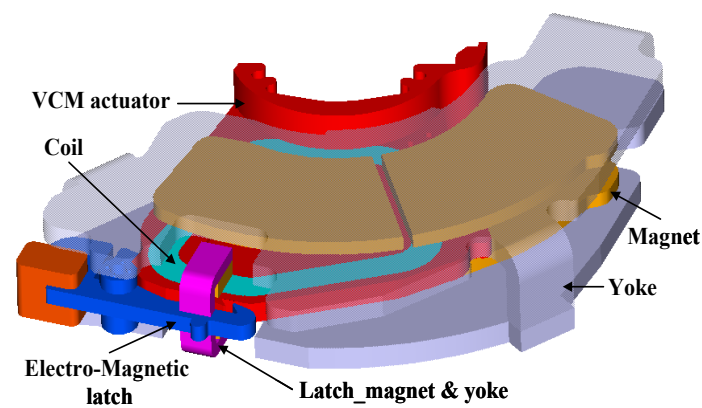

Fig. 2 Structure of the proposed magnetic latch using electro-magnetic of VCM actuator

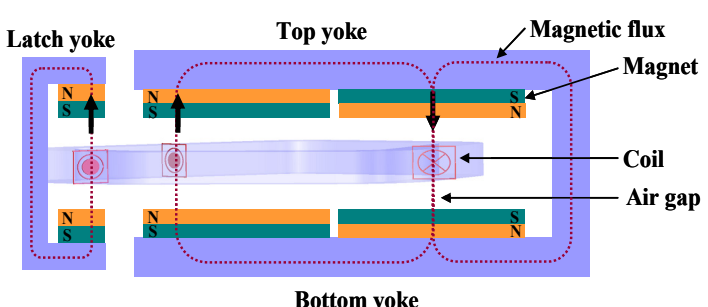

Fig. 3 Cross-sectional view of proposed electro-magnetic latch

자석과 래치 요크로 이루어진 구조를 갖는다. 또한, 래치에 코일 전류 인가시 전자기력을 발생시키기 위 해 코일이 래치 쪽까지 확장되어 있다.

$\mathrm{VCM}$ 액추에이터가 로딩되기 위해 Fig. 3 과 같이 자석의 $\mathrm{N}$ 극과 $\mathrm{S}$ 극이 배열되어 있으며, 코일에 시계 방향으로 전류가 인가할 때 플레밍의 왼손 법칙에 의해 $\mathrm{VCM}$ 액추에이터는 반시계 회전 방향으로 힘 을 받게 되어 로딩하게 된다. 또한, 동시에 래치가 언래치되기 위해 Fig. 3과 같이 래치 자석의 N극과 $\mathrm{S}$ 극이 배열되어 있으며, 코일 전류 인가시에만 코 일이 받는 힘의 반작용에 의해 래치가 언래치되는 힘이 발생된다.

그러나 Fig. 3과 같이 VCM 액추에이터 코일에 전류 비인가시(언로딩시), 래치에 부착되어 있는 자 석과 $\mathrm{VCM}$ 자석이 같은 극의 배열이 되어 척력이 작용하게 된다. 따라서 이 때 $\mathrm{VCM}$ 자석과 래치 자 석에 의해 척력이 발생하여 래치는 항상 열리려고 한다. 동시에 래치에 부착되어 있는 요크에 의해 $\mathrm{VCM}$ 자석과 항상 인력이 작용하게 되어 항상 래 치는 닫히려고 한다. 따라서 전류 비인가시 래치에 동시에 발생하는 인력과 척력, 두 힘의 크기를 조절 하여 식(1)과 같이 요크에 의한 인력이 크도록 설 


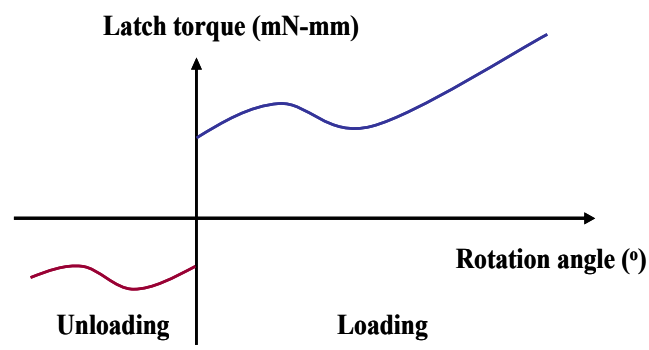

Fig. 4 Torque applied to latch in loading/unloading

계하여, 래치 요크에 의한 인력에서 래치 자석에 의 한 척력을 뺀 힘만큼 래치에 힘이 작용하여 래치를 항상 락킹되도록 설계할 수 있다.

- 언로딩(unloading) 조건 : 전류 비인가시

$$
T_{\text {no_current }}=T_{\text {magnet }}-T_{\text {yoke }}<0
$$

- 로딩(loading) 조건 : 전류 인가시

$$
T_{\text {current }}=T_{\text {electromagnetic }}+T_{\text {magnet }}-T_{\text {yoke }}>0
$$

그리고 $\mathrm{VCM}$ 액추에이터 코일에 전류가 인가되 었을 경우(로딩시), 식(2)와 같이 $\mathrm{VCM}$ 코일과 래 치 자석에 의해 발생하는 전자기력이 $\mathrm{VCM}$ 자석과 래치 자석에 의한 인력보다 더 크게 되어 래치에서 언래치하는 힘이 발생하게 되어 래치가 구속 상태 에서 풀려지며 $\mathrm{VCM}$ 액추에이터가 로딩하게 된다.

따라서 이러한 작동 메커니즘을 $\mathrm{VCM}$ 액추에이 터 전류 비인가시(언로딩)과 전류 인가시(로딩)시 래치에 작용하는 토크의 크기를 통해 도식적으로 나타내면 Fig. 4와 같다. 이러한 일련의 작동을 원활 하게 하기 위해서는 래치 자석과 래치 요크의 크기, 두께와 $\mathrm{VCM}$ 자석과의 거리에 대한 최적 설계를 수행하여야 한다. 그리고 래치 작동을 위한 코일 형 상 변경에 따른 액추에이터 구동을 기존 액추에이 터와 비교하여 검증할 필요가 있다.

\section{$3.2 \mathrm{VCM}$ 구동 토크}

자석 래치를 움직임을 구현하기 위해서는 먼저 원래 $\mathrm{VCM}$ 코일과 다르게 Fig. 2에 보여지는 형태 로 코일 부분의 형상이 바뀌는데 이러한 형상 변경 이 $\mathrm{VCM}$ 액추에이터 구동에 영향을 주는지를 판별 해야 한다. 제안한 코일 형태를 바꾼 경우와 원래의

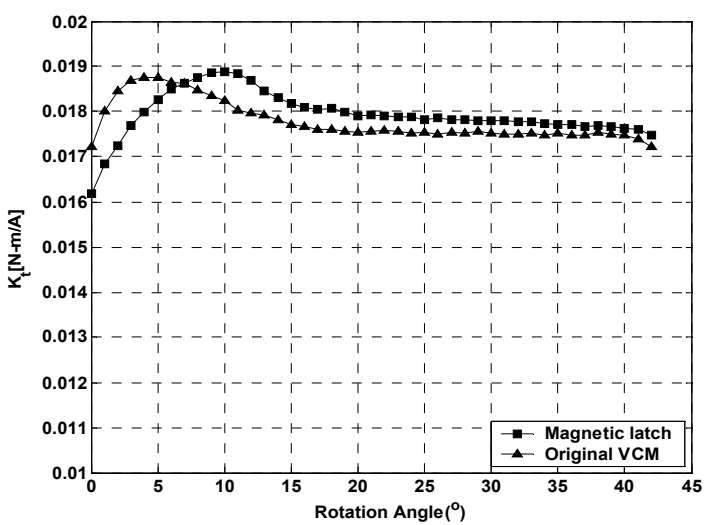

Fig. 5 Torque constant of original VCM and magnetic latch VCM

Table1 Comparisons on the performances of VCM types

\begin{tabular}{l|c|c|c|c}
\hline \hline \multicolumn{2}{|c|}{} & $\begin{array}{c}\text { Original } \\
\text { VCM }\end{array}$ & $\begin{array}{c}\text { Magnetic } \\
\text { latch VCM }\end{array}$ \\
\hline \multirow{3}{*}{$K_{t}$} & \multirow{3}{*}{$\begin{array}{c}\text { Data } \\
\text { area }\end{array}$} & Average & 0.01753 & 0.01782 \\
\cline { 3 - 5 } & & Max. & 0.01772 & 0.01817 \\
\cline { 3 - 5 } & & Min. & 0.01722 & 0.01748 \\
\cline { 3 - 5 } & Linearity (\%) & 1.76 & 1.93 \\
\hline \multicolumn{3}{l}{ Max. yoke flux [T] } & 2.66 & 2.56 \\
\hline
\end{tabular}

형태를 갖는 경우에 대해서 액추에이터 회전각도에 따른 코일에 가해진 단위 전류당 토크 값을 나타내 는 토크 상수(torque constant, $K_{t}$ )값을 구하여 비교한 결과를 Fig. 5 에 나타내었다. 이 연구에서는 상용 전 자기 해석 툴인 J-MAG을 이용하여 전자기력 해석을 수행하였다. 상하 요크의 재질은 $\mathrm{SPCC}$ 를 사용하였 고, 자석은 희토류계 자석인 $\mathrm{N} 48 \mathrm{H}$ (Shinetsu)를 사용 하였다.

이 논문에 제안된 자석 래치의 경우, 코일 형상 변경에 의해 토크 상수 프로파일이 원래 $\mathrm{VCM}$ 액 추에이터와 비교하여 Fig. 5와 같이 약간의 차이를 보임을 알 수 있다. 이 차이가 실제 액추에이터 구 동에 영향을 주는지를 알아보기 위해 디스크의 데 이터 영역인 15 도에서 42 도까지의 토크 상수의 최 대, 최소, 평균에 대하여 원래 $\mathrm{VCM}$ 액추에이터와 비교하여 그 결과를 Table 1에 정리하였다.

Table 1의 결과를 통해 실제 $\mathrm{VCM}$ 액추에이터 구동 특성에 영향을 미치는 데이터 영역에서의 토 크 상수의 경우, 원래 $\mathrm{VCM}$ 액추에이터의 토크 상 
수 값과 비교하여 크게 벗어나지 않아 동일한 액추 에이터 성능을 가짐을 확인할 수 있다.

또한, 제어 측면에서의 성능을 확인하기 위해 토 크 상수의 선형성(linearity)를 식 (3)과 같이 계산할 수 있다. 이 때, 기존 $\mathrm{VCM}$ 액추에이터에 비하여 약 $0.17 \%$ 의 큰 값을 갖는다. 그러나 일반적으로 선형성의 허용 오차를 $4 \%$ 이내로 기준을 잡기 때 문에 제어 측면에 문제가 없다. 따라서 이 연구의 자석 래치를 위해 코일 형상을 변경하는 것이 원래 $\mathrm{VCM}$ 액추에이터 성능에 영향을 미치지 않는 것을 확인할 수 있다.

$$
\operatorname{Linearity}(\%)=\frac{\left(K_{t \_ \text {Average }}-K_{t_{-} \text {Min }}\right)}{K_{t_{-} \text {Average }}} \times 100
$$

\section{3 자석 래치(magnetic latch) 토크}

자석 래치의 전류 비인가시(언로딩)와 전류 인가 시(로딩) 조건에서 래치 및 언래치 방향으로 회전각 에 따른 토크를 구하기 위해 Fig. 6과 같이 상용 해 석 툴인 J-MAG을 이용하여 해석하였다. 그리고 그 결과는 Fig. 7과 8에 나타내었다.

3.1절에서 언급한 작동 메커니즘과 같이 전류가 인가되었을 때, 래치가 언래치되는 방향으로 토크가 작용함을 Fig. 7에서 확인할 수 있다. 그리고 전류 비인가시에는 래치에 작용하는 토크가 래치가 항상 닫히도록 하는 방향으로 음수 토크가 작용함을 Fig. 8의 결과로 알 수 있다.

$\mathrm{VCM}$ 액추에이터 로딩시 자석 래치의 언래치 조 건을 살펴보면, $\mathrm{VCM}$ 액추에이터의 최대 $450 \mathrm{~mA}$ 를 입력 값으로 주었을 때 Table 2의 물성값과 식 (4) 를 이용하여 최대 각가속도를 구하여 보면, 로딩 구 간에서의 회전 각도에 따라 $1.8 \sim 17 \mathrm{krad} / \mathrm{s}^{2}$ 의 값을 가진다. 반면, 자석 래치의 경우 Fig. 7과 같이 로딩 구간에서의 토크를 이용하여 각가속도를 구하여 보 면 대략 $130 \sim 210 \mathrm{krad} / \mathrm{s}^{2}$ 의 값을 갖는다. 따라서 $\mathrm{VCM}$ 액추에이터 로딩시 자석 래치가 $\mathrm{VCM}$ 액추 에이터에 비하여 훨씬 더 빠르게 열리도록 되어 있 기 때문에 $\mathrm{VCM}$ 액추에이터 로딩에 문제가 없음을 알 수 있다.

$$
T_{\text {latch }}=I_{\text {latch }} \cdot \alpha
$$

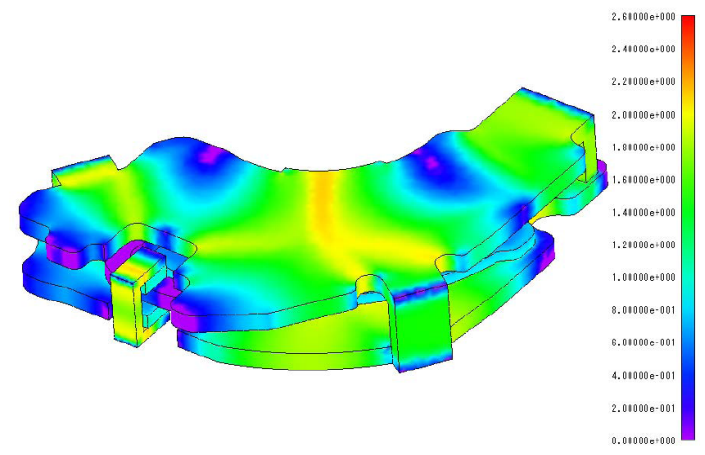

Fig. 6 Electromagnetic simulation result using J-MAG

Table 2 Properties of VCM actuator

\begin{tabular}{c|c|c}
\hline \hline Properties & Magnetic latch & VCM actuator \\
\hline Mass $(\mathrm{g})$ & 0.54 & 3.65 \\
\hline Inertia $\left(\mathrm{g} \mathrm{mm}^{2}\right)$ & 1.62 & 491 \\
\hline
\end{tabular}

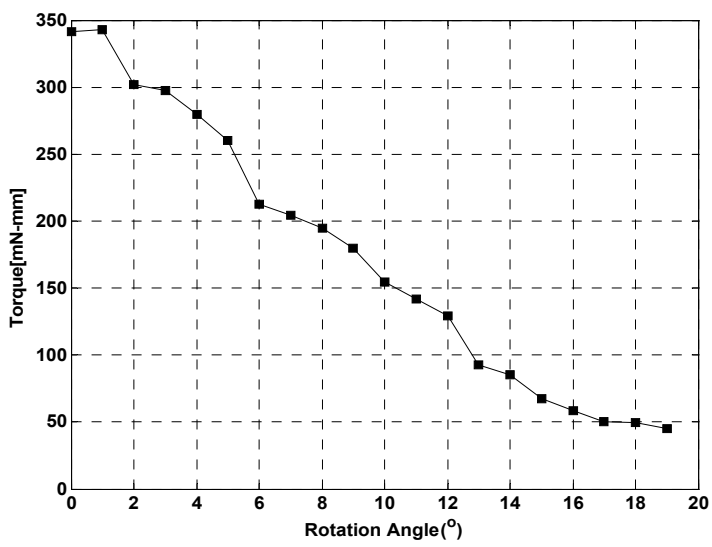

Fig. 7 Loading magnetic latch torque

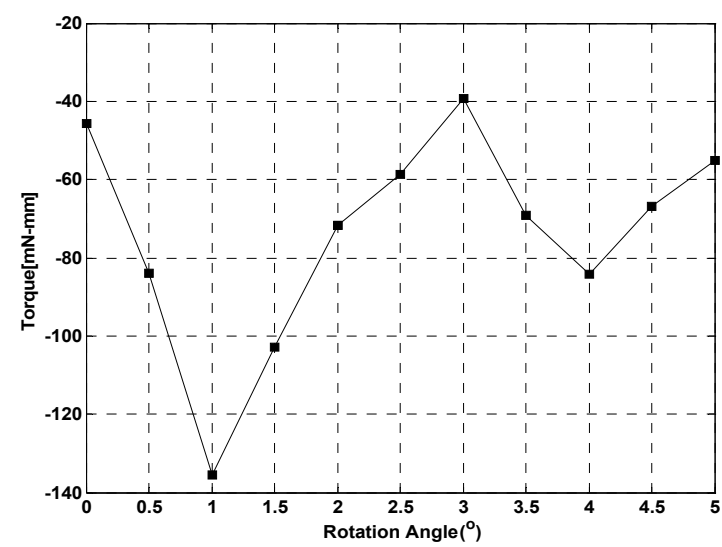

Fig. 8 Unloading magnetic latch torque 


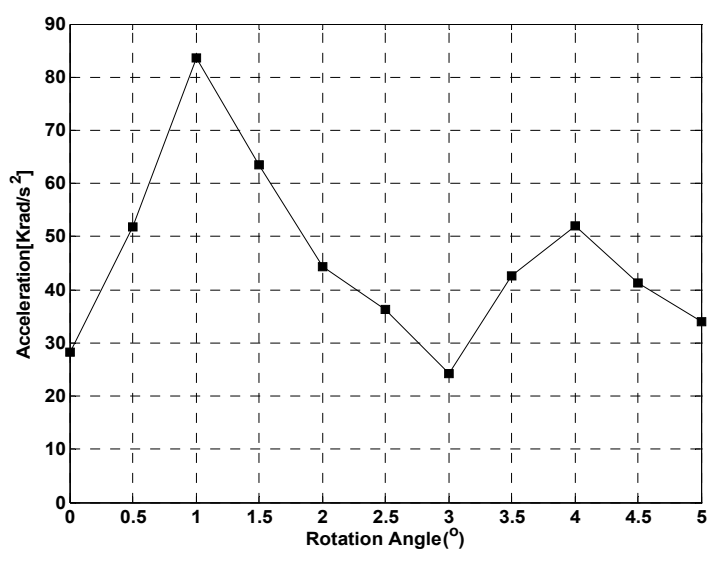

Fig. 9 Magnetic latch acceleration of unloading

\subsection{Shock 성능 예측}

3.1절의 작동 메커니즘과 같이 $\mathrm{VCM}$ 액추에이터 코일에 전류 비인가시 $\mathrm{VCM}$ 자석과 래치 자석에 의한 척력이 발생하고 동시에 $\mathrm{VCM}$ 자석과 래치 요크에 의한 인력이 발생하게 된다. 따라서 래치 요 크에서 발생하는 인력(음수 토크)이 래치 자석에 의 한 척력(양수 토크)보다 크게 설계되어 있어 Fig. 8 과 같이 $\mathrm{VCM}$ 코일에 전류가 비인가시 항상 자석 래치가 락킹(음수 토크)된다. 이로 인해 $\mathrm{VCM}$ 액추 에이터는 자석 래치에 의해 비동작시 외부 충격과 진동에 항상 락킹되도록 설계되어 있음을 알 수 있 다. 따라서 비작동시 외부 충격이 가해졌을 때 자석 래치의 충격 성능을 예측하는 것이 필요하다.

이 논문의 래치는 질량 균형(mass balance)을 회전 중심에 일치하도록 설계하여 선형 충격(linear shock) 에 대응하도록 되어있으므로 회전 충격(rotary shock) 에 대하여 충격 성능을 살펴보아야 한다. 일반적으 로, 드라이브 규격으로 비작동시 회전 충격(nonoperating rotary shock)에 의해서 $20 \mathrm{krad} / \mathrm{s}^{2}$ 이상의 각가속도를 확보하도록 요구하고 있다. 따라서 이 연구에서 설계된 자석 래치의 비작동시 회전 충격 에 대한 각가속도를 구하고자 한다. Table 2의 자석 래치와 $\mathrm{VCM}$ 액추에이터의 물성값과 식 (4)를 이용 하여 각도에 따른 각가속도를 구하면 Fig. 9와 같다. Fig. 9에서 보는 바와 같이 자석 래치의 초기 위치 에서 약 $30 \mathrm{krad} / \mathrm{s}^{2}$ 의 각가속도 값을 가진다. 또한, $30 \mathrm{krad} / \mathrm{s}^{2}$ 이상의 큰 충격으로 인해 자석 래치가 초기 위치를 벗어날 경우에도 래치 회전 각도에 따 라 최대 $80 \mathrm{krad} / \mathrm{s}^{2}$ 이상의 각가속도 값을 갖게 되
어 큰 외부 충격에도 래치가 락킹하여 우수한 래치 성능을 보임을 확인할 수 있다.

\section{4. 결 론}

이 연구에서는 $\mathrm{VCM}$ 액추에이터의 전자기력을 이용한 새로운 메커니즘을 가지는 자석 래치를 제 안하였고, 그 성능을 전자기 해석 시뮬레이션을 통 해 확인하여 기존 관성 래치의 한계를 극복하였다. 이 논문의 자석 래치는 코일에 전류 인가시 래치에 발생된 전자기력에 의해 래치가 자동으로 열리는 구조를 통해 자동 언래치되도록 한다. 또한, 드라이 브 비작동시에는 래치 요크와 $\mathrm{VCM}$ 액추에이터 자 석과의 인력에 의해 항상 락킹되어 어떠한 외부 충 격에도 드라이브를 항상 보호할 수 있는 작동 메커 니즘을 가진다. 따라서 기존 $\mathrm{VCM}$ 액추에이터의 리 트랙트 핀과 래치 볼이 불필요하여 기존 관성 래치 과 비교하여 간단한 구조를 가진다.

이를 위해 이 연구에서는 래치 작동에 사용될 래 치 자석과 요크를 시뮬레이션을 통해 최적 설계를 구현하였다. 또한, $\mathrm{VCM}$ 액추에이터의 작동과 자석 래치 작동을 위한 구간으로 코일 형상을 변경하고 그에 따른 $\mathrm{VCM}$ 액추에이터 성능이 기존과 동일한 수준임을 시뮬레이션을 통해 확인하였다. 그리고 이 연구의 자석 래치는 우수한 충격 성능이 보장됨을 확인하였다.

\section{참 고 문 헌}

(1) Kim, Y. S., Kim, K. H., Lee, S. Y., Yu, S. H. and Kim, S. K., 2004, "Inertia Latch Design for Micro Optical Disk Drives," Transactions of the Korean Society for Noise and Vibration Engineering, Vol. 14, No. 4, pp. 287 294.

(2) Chang, J., Monajemy, R., Pham, T., Baral, D. and Byun, Y., 2005, "Pawl Latch Mechanism Design and Control for Load/unload Technology," Microsystem Technologies, Vol. 11, pp. 747 750.

(3) Byun, Y., Kang, J., Chang, J., Sharma, V. and Lee, H. J., 2002, "Impact Rebound Type Inertia Latch for Load/unload Technology," Microsystem Technologies, Vol. 8, pp. 37 40. 
(4) Albrecht, T. R. and Sai, F., "Load/Unload Technology for Disk Drives," IEEE Transactions on Magnetics, Vol. 35, pp. 857 862.

(5) Kim, K. H., Hong, M. P., Kim, Y. S. and Kim, Y. J., 2008, "Automatic Latch System Using Electromagnetic Force of VCM Actuator," Samsung
Electronics Co., No. P2008-0016983.

(6) Kim, K. H., Oh, D. H., Kim, Y. S., Hong, M. P. and Kim, Y. J., 2008, "Automatic Latch System Using Electromagnetic Force of VCM Actuator," Samsung Electronics Co., Korea Patent No. P2008-0070191. 